\title{
THE GREEN ECONOMY - SAVING THE ENVIRONMENT?
}

\author{
Vaduva Alina Corina \\ Sabina Trading Company SRL, Romania \\ DOI: https://doi.org/10.36997/ARA2021.298
}

\begin{abstract}
The future of the national economy is based on the green economy because after the multitude of discussions it was concluded that this concept is essential in order to achieve the proposed objectives. The "Green economy" is meant to foster sustainable development, especially in the long run, by creating an enabling environment through research, innovation and a knowledge-driven concern. At the basis of the transition to a "green economy" is the practice of a typology of economy based exclusively on policies and investments, the latter linking economic development, health, biodiversity and last but not least climate change, both long-term and long-term medium. As at present the practiced economic system is in full collapse, it was decided that it is necessary to rethink it from all points of view. So, the transition to the green economy is considered as the main solution that aims to adapt the economy and with it its evolution and new challenges that arise globally, by increasingly integrating the environment into the paradigm that refers to lasting development.
\end{abstract}

Keywords: green economy; sustainable development; economical growth

JEL Classification: Q56

\section{Introduction}

Over the years, the environment and its protection has become a global priority, which is why each state has chosen to adopt a legislative and executive system on environmental protection.

The extremely high number of problems that appeared as a result of economic crises, which can no longer be solved, determined the creation of this concept, the latter seeking to find concrete solutions that can be applied in the international problem of environmental development. In the long run, we want to find solutions that eliminate poverty on the one hand and improve the quality of life on the other. In order to achieve all these needs and more precisely the transformation of sustainable economic development, it is necessary to have a transition with multiple implications made both at the level of governments on the one hand and at the level of the private environment on the other hand.

"Green economy" has become a hotly debated topic globally, this concept aiming to find concrete solutions and long-term alternatives on the international issue of environmental development in order to eliminate as much as possible the poverty of the population on the one hand and improving the quality of life on the other hand. Regarding this new concept, called Green Economy, we can mention the fact that it involves a series of structural changes to the 
advantage of a wide category of sectors, with a very wide area of action.

The process of transition to "Green economy" involves the practice of an economy based on both investment and policies. In order to resume global economic growth, experts believe that links must be made between economic development, climate change, biodiversity on the one hand and on the other hand the long-term and medium-term well-being and health of the population. As sustainable development is considered to be the basis for economic recovery both at European and global level, these premises listed above must be connected. Globally, sustainable development is considered to be the basis for the resumption of economic growth, and in order for this to be achieved, it is necessary that there be a connection between these premises.

\subsection{The European Union and its involvement in the transition to the "Green} economy"

At the level of the European Union, it was found that a very important role in economic growth is played by nature and more specifically I say its value and importance. When we touch on this topic, we notice that the concept of green economy intervenes in the discussion, a concept that concentrates its attention and sets as its objective the transition to an economy that is closely related to sustainable development. it is necessary for all countries to make a joint effort in the first place, in the second to initiate awareness campaigns on this new phenomenon, and in the last, but not the last to offer timely and applicable solutions.

In order to be able to implement in each state this concept of green economy, it is imperative to have a deep involvement of the business environment on the one hand and of consumers on the other hand, and at the same time, along with them both national and international governing bodies propose and adopt them. Due to climate change in recent years, it has been concluded that the sustainable use of resources and the adoption and use of the green economy have become a priority, an importance that the entire population must understand.

Through the green economy, the aim is to create new jobs on the one hand and promote economic growth on the other, the use of natural resources along with energy, new technologies and of course non-polluting production methods being the main goals of this new economy. The creation of new models of sustainable production and consumption is a priority of the green economy, the only condition being that they do not force the ecosystem. The close link between the proper use of natural resources on the one hand and the conservation of the environment on the other is complemented by sustainable development, the latter implying dynamism, adaptation and research, or in a word requires permanent changes. 


\subsection{Political tools used by UE for transition to the Green Economy}

Within the ecological economy there are a series of political instruments that can be grouped in turn into several categories, as follows:

- fair pricing

- public procurement policies

- ecological fiscal changes (so-called reforms)

- public investments that concentrate their area of interest around sustainable infrastructure

- public support in the field of ecological technologies for both research and development in this regard.

- social policies that aim to reconcile social objectives on the one hand with economic policies on the other hand

\section{Top Yale's Composite Environmental Performance Index (PPE)}

This top, called EPI, has 37 states and focuses its analysis on the Yale's Composite Environmental Performance Index (EPI), through which it analyzes a considerable number of indicators (several dozen), including air quality. biodiversity and even waste management. In this analysis, attention was focused only on the countries that the World Bank considers to have high incomes.

Table 1.

Top Yale's Composite Environmental Performance Index (PPE)

\section{Topul țărilor bogate ale lumii cu cele mai verzi economii}

\begin{tabular}{|c|c|c|c|c|}
\hline \multicolumn{2}{|c|}{ Poz. Țară } & \multirow{2}{*}{$\begin{array}{l}\text { Scor } \\
82,5\end{array}$} & Poz. Țară & \multirow{2}{*}{$\begin{array}{l}\text { Scor } \\
77,7\end{array}$} \\
\hline 1 & DANEMARCA & & NORVEGIA & \\
\hline 2 & LUXEMBURG & 82,3 & GERMANIA & 77,2 \\
\hline 3 & ELVETIIA & 81,5 & $\ldots$ & \\
\hline 4 & MAREA BRITANIE & 81,3 & 21 CEHIA & 71,0 \\
\hline 5 & FRANTTA & 80,0 & 32 ROMÂNIA & 64,7 \\
\hline 6 & AUSTRIA & 79,6 & 33 UNGARIA & 63,7 \\
\hline 7 & FINLANDA & 78,9 & POLONIA & 60,9 \\
\hline 8 & SUEDIA & 78,7 & SURSĂ: Yale's comp & $\begin{array}{l}\text { onmenta } \\
\text { ndex (EP) }\end{array}$ \\
\hline
\end{tabular}

Source:Yale's Composite Environmental Performance Index (EPI) 
The beginning of 2021 at the same time as the end of 2020 ranks in the first 10 positions of this top a number of 10 countries, most of which are European (except Switzerland and Great Britain), and later on the 12th place finding Japan, followed by Australia and New Zealand, from this top noting the fact that the European Union has implemented the measures it has proposed in order to achieve the predetermined greening objective. In the first chart (Chart 1) we notice the first 10 countries that are in the leading positions of the top, and in the second chart (Chart 2) we notice the countries that are at the bottom of the ranking.

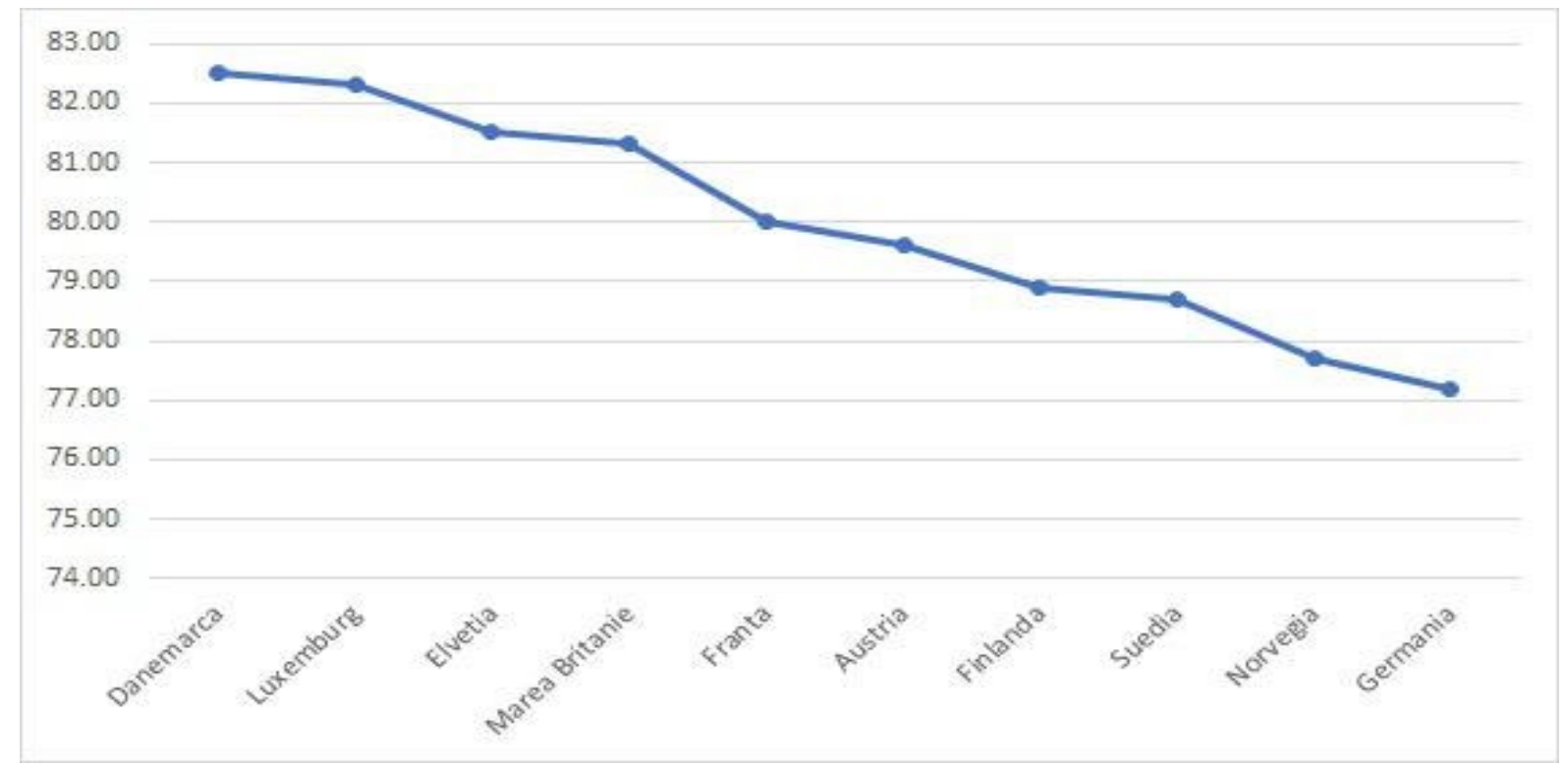

Source: Personal processing of data on Yale's Composite Environmental Performance Index (EPI)

Chart 1. First 10 countries positions of EPI Top

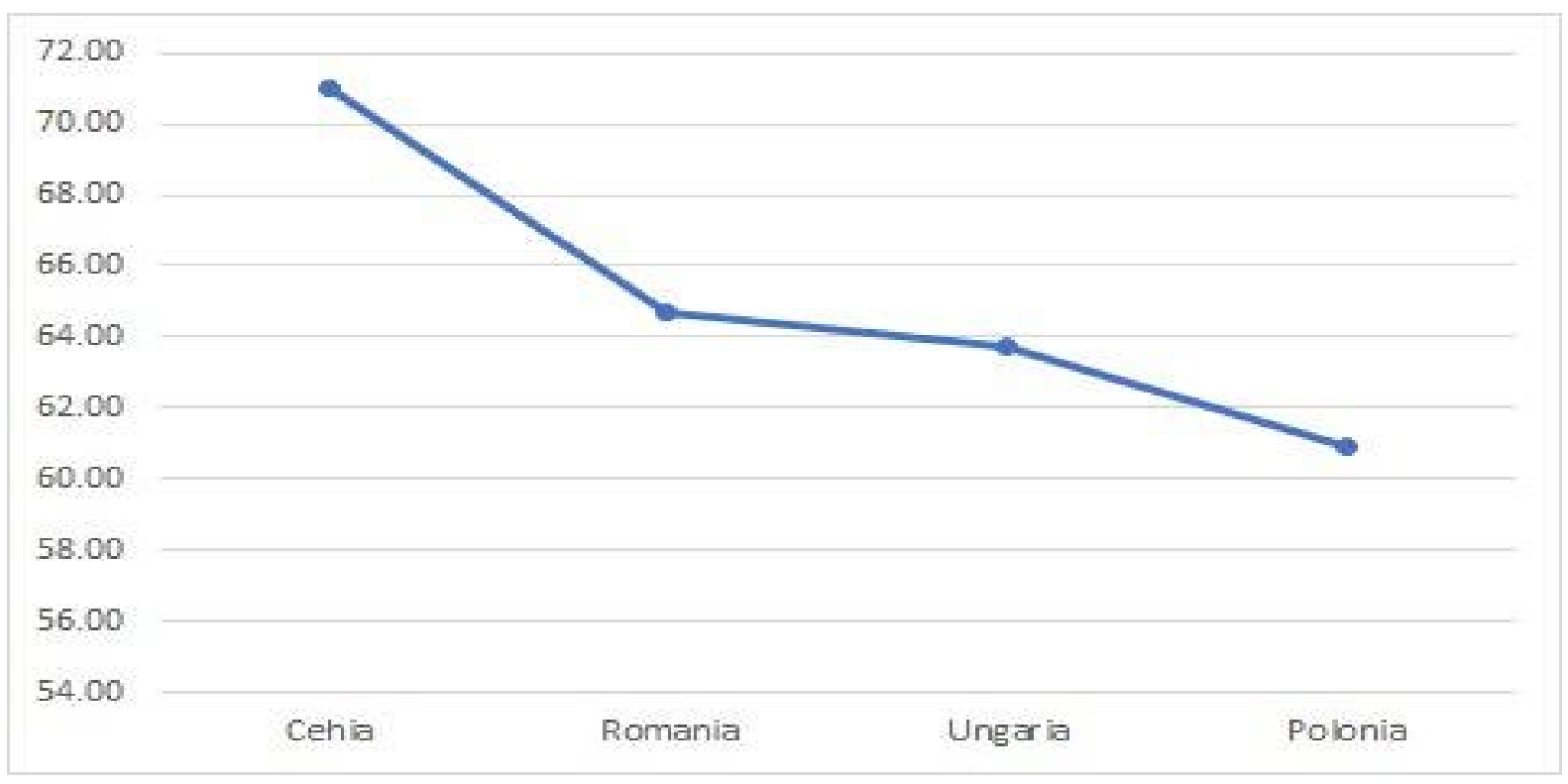

Source: Personal processing of data on Yale's Composite Environmental Performance Index (EPI)

Chart 2. Last 4 countries positions of EPI Top 
From Chart 2 we notice that the countries ranked at the bottom of the ranking, countries in which Romania falls, being on position 32, are countries that also belong to the European Union, which indicates that the measures that the EU has applied have given a high yield in better developed countries.

Therefore, we note that through the two graphs we can conclude that at the top of the rankings we find most of the richest countries in the world, which shows that their agenda has long been the issue of environmental protection. For many years now and until now, discussions have been debated at European and global level on reducing pollution, the idea of a green economy that is environmentally friendly being on the list of the respective authorities.

\section{Conclusions}

Long-term sustainable development is the main objective of the green economy, which also focuses on creating its own framework based on knowledge, innovation and research, used to achieve the proposed objective.

The interest for defining and implicitly applying various aspects of the green economy or the green economy, represents an objective of the EU, as the latter focuses its attention on the renewal of the sustainable development activity worldwide.

The effects of the crisis and its management are topics covered by the new economic system, a system based on sustainable development and which is intended to become the real solution to social, economic and environmental problems. It is desired to create conditions for economic growth on the one hand, and on the other hand to reduce poverty and in order to be able to create these conditions it is necessary to take measures based on appropriate policies in this regard.

Favoring economic growth and also creating new jobs are just two examples through which we can see that the green economy aims to use natural resources with energy and new technologies along with a series of non-polluting production methods. The main way in which this can be done is to create new models of sustainable consumption and production, all this being possible only with one condition: not to force the ecosystem. Proper use of natural resources along with environmental conservation are closely linked to sustainable development and more specifically what it entails (ie dynamism, the need for permanent change, research and adaptation. 


\section{Bibliography:}

1. Marinela Gheres, Teodor Rusu, Marius Ioan Gheres - "Economia mediului si protectia agroecosistemelor"

2. Victor Danciu - "Marketing ecologic: Etica verde a productiei si consumului"

3. Carmen Zaharia - "Legislatia pentru protectia mediului"

4. http:// Yale's Composite Environmental Performance Index (EPI)

5. https://ec.europa.eu/eurostat/statisticsexplained/index.php?title=Environmental_economy

\%E2\%80\%93_statistics_by_Member_State\&oldid=491973\&fbclid=IwAR1aSKfRtgglZII OXKBDoStPOXmv1RKr_b8reKZ8gToMaTYhXNXVjLKbcfc

6. https://ec.europa.eu/environment/greengrowth/index_en.htm?fbclid=IwAR0hIBJfj_yCK Xeg32rti1gho8VkTCMz5DgTeVg4KIEn1UqUep415GmERCE

\section{Contact information for the author:}

Vaduva Alina Corina

Sabina Trading Company SRL, Romania

e-mail: cori_alina@yahoo.com 